\title{
Inflammatory bowel disease nurse specialists for patients on biological therapies: a nationwide Italian survey
}

\author{
Alessandra Guarinia , Francesca De Marinis a , Anna Kohnn, Nicoletta Orzesc, Renata D'Incàd,

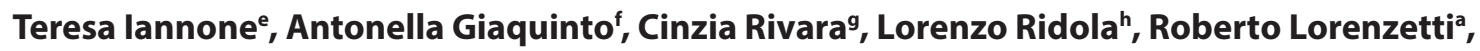 \\ Angelo Zulloa, Italian IBD Nurses Study Group
}

Nuovo Regina Margherita Hospital, Rome; San Camillo-Forlanini Hospital, Rome; Polo Ospedaliero Gorizia-

Pordenone, Gorizia; University of Padua; Santa Maria degli Ungheresi Hospital, Polistena, Reggio Calabria; Tor Vergata University, Rome; Ciriè Hospital, Turin; Sapienza University of Rome, Polo Pontino Hospital, Latina, Italy

Abstract

\begin{abstract}
Background Management of inflammatory bowel disease (IBD) patients requires a multidisciplinary approach. Among the working team, the role of IBD nurse is expected to be particularly relevant when managing patients receiving biological therapies. We performed a survey to assess the presence of IBD nurse in centers where patients were receiving biologics.
\end{abstract}

Methods For this Italian nationwide survey a specific questionnaire was prepared. IBD nurse was defined as a nurse directly involved in all phases of biological therapy, from pre-therapy screening, administration and monitoring during therapy, to follow up performed by a dedicated helpline, completed a specific training on biological therapy therapy, and observed international guidelines.

Results A total of 53 Italian IBD centers participated in the survey, and 91 valid questionnaires were collected. Overall, 34 (37.4\%) nurses could be classified as IBD specialists. IBD nurses had a significantly higher educational level than other nurses, they were more frequently operating in Central or Southern than in Northern Italy, they were working in an Academic center rather than in a General hospital, and in IBD centers with $>25$ patients on biological therapy. On the contrary, mean age, gender distribution, years of nursing, and years working in the IBD unit did not significantly differ between IBD and other nurses.

Conclusions Our nationwide survey showed that the presence of an IBD nurse is still lacking in the majority of Italian IBD centers where patients receive biological therapies, suggesting a prompt implementation.

Keywords Inflammatory bowel disease, biological therapy, management, nursing

Ann Gastroenterol 2016; 29 (4): 1-6

${ }^{\mathrm{a}}$ Gastroenterology and Digestive Endoscopy, Nuovo Regina Margherita Hospital, Rome (Alessandra Guarini, Francesca De Marinis, Roberto

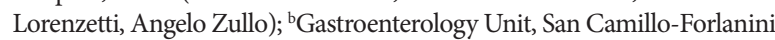
Hospital, Rome (Anna Kohn); ' Gastroenterology Unit Polo Ospedaliero Gorizia-Pordenone, Gorizia, Italy (Nicoletta Orzes); ${ }^{\mathrm{D}}$ Department of Surgical, Oncological and Gastroenterological Sciences, Gastroenterology Section, University of Padua (Renata D'Incà); ${ }^{e}$ Gastroenterology and Digestive Endoscopy, Santa Maria degli Ungheresi Hospital, Polistena, Reggio Calabria (Teresa Iannone); ${ }^{\mathrm{f}}$ Endoscopy Unit, Tor Vergata University, Rome (Antonella Giaquinto); ${ }^{\mathrm{g} C i r i e ̀ ~ H o s p i t a l, ~ T u r i n ~(C i n z i a ~}$ Rivara); ${ }^{\mathrm{h}}$ Gastroenterology Unit, Sapienza University of Rome; Polo Pontino Hospital, Latina (Lorenzo Ridola); Italian IBD Nurses Study Group, Italy

Conflict of Interest: None

Correspondence to: Dr Angelo Zullo, Gastroenterologia ed Endoscopia Digestiva Ospedale Nuovo Regina Margherita, Via Emilio Morosini 30, 00153 Rome, Italy, Tel.: +39 06 58446608, Fax: +39 0658446533 ,

e-mail: angelozullo66@yahoo.it

Received 20 May 2016; accepted 28 June 2016; published online 21 July 2016

DOI: http://dx.doi.org/10.20524/aog.2016.0073

\section{Introduction}

Inflammatory bowel disease (IBD) defines chronic conditions of which Crohn's disease and ulcerative colitis are the most predominant forms $[1,2]$. These diseases generally start at a young age, affect the quality of life of both patients and their families, and cause a high level of healthcare resource consumption [3]. A multidisciplinary approach provided by different professionals - physicians, nurses, psychologists, and dieticians - is advisable for an appropriate care of IBD patients $[4,5]$. Among them, trained nurses play an important role [6-8]. The Nurses-European Crohn's \& Colitis Organisation (N-ECCO) Consensus statements defined the basic and advanced nursing care ('Fundamental IBD Nurse' and 'Advanced IBD Nurse') required to address patients' needs [9]. Shortly, IBD nurses involved in the basic nursing care should have basic knowledge on the diagnosis and therapy of IBD as well as how this illness affects health-related quality of life. They should develop an empathetic role towards IBD 
patients to favor communication on pain, fatigue or sexual concerns. Moreover, IBD nurses should collaborate with healthcare professionals in managing fistulas, stomas, fecal incontinence, and the nutritional status of patients. Therefore, both clinical experience and a specific training are required for IBD nurses. To date, the title - as well as the level of training and/or education - of IBD nurse is not formally recognized in Italy, even if the need for IBD basic and advanced nursing care has been recently underlined in an official document of National Health planning [10].

The presence of IBD nurse in a multidisciplinary team is expected to be particularly relevant when managing those IBD patients receiving biological therapies due to a more severe disease [11]. Indeed, these patients require a pre-therapy screening, strict follow up, scheduled controls, and facilities for unscheduled visits due to potential adverse events, and IBD nurses are actively involved in any of these processes. A recent N-ECCO survey of nursing practice in caring IBD patients in Europe demonstrated that the role of nurses does exist in various settings within hospital care, providing complex management and autonomous nursing care in a range of services [6]. However, only few $(n=4)$ nurses participated from Italy. Therefore, with the auspices of the ANOTEANIGEA (National Association of Endoscopic Techniques Operators - National Association of Gastroenterology Nurses and Associates), we performed an Italian nationwide survey to assess the presence of IBD nurse in centers where patients receive biological therapies. As a secondary endpoint, the unmet needs for professional formation of these nurses were recorded.

\section{Materials and methods}

\section{Questionnaire}

A specific questionnaire was prepared to evaluate whether an IBD nurse was available in Italian centers providing biological therapies for IBD patients (Appendix). This included the following 3 parts: a) demographic data, general training, and degree (8 items); b) information on specific roles directly played in caring IBD patients on biological therapy (8 items); c) information on specific training for IBD nursing ( 7 items). The questionnaire also invited every nurse to write down which the unmet needs in the education process of an IBD nurse were.

A nurse involved in the administration of biologics was arbitrarily defined as IBD nurse when he/she was in charge of the following roles: a) organization of biological therapy (screening pre-therapy, appointments scheduling, and follow up); b) administration of biological therapy with monitoring during the infusion (infliximab) or patient's (or family) training for a correct subcutaneous injection (adalimumab); c) dedicated helpline with triage for accesses to the clinic during therapy; d) knowledge and observation of all N-ECCO Consensus statements for IBD [9]; and e) attendance of a course specifically dedicated to biological treatment or a specific training by an experienced colleague.

\section{Participants}

An invitation letter containing the survey protocol was sent by e-mail to all ANOTE-ANIGEA associates. In addition, when the contacted associate declined the participation or was lacking in a specific Italian region, at least another IBD center was contacted for an appropriate coverage of the national territory. Only nurses working in those IBD centers where at least 10 patients receiving biological therapies were invited to participate. Following acceptance and satisfaction of the inclusion criteria the questionnaire was sent by mail, and the filled documents were collected in a single center for data analysis. One repeat telephone call was performed when the reply of the participant was insufficient.

\section{Data analysis}

Data of all questionnaires were individually rowed into a computerized spreadsheet for statistical analysis. T- and chisquare tests were used as appropriate. A P value less than 0.05 was considered significant.

\section{Results}

A total of $53(72.6 \%)$ of 73 contacted centers participated in the survey, with a median of 2 (range: 1-14) participating centers per region. Overall, 93 questionnaires were received, with a median of 1 (range 1-5) from each center, but 2 of them containing incomplete data were excluded from the analysis. The demographic characteristics of the participants are given in Table 1.

According to the predefined criteria, a total of 34 (37.4\%) nurses could be classified as IBD specialists. As shown in Table 2, IBD nurses had a significantly higher educational level

Table 1 Characteristics of participants

\begin{tabular}{lc}
\hline Characteristic & Value \\
\hline Age (Mean \pm SD) (years) & $47.2 \pm 6.2$ \\
Male/female & $14 / 77$ \\
$\begin{array}{l}\text { Educational level } \\
\text { Diploma/Degree/Master }\end{array}$ & $79 / 9 / 3$ \\
Years of nursing (Mean \pm SD) & $23.9 \pm 7.5$ \\
Years of working in a Gastroenterology & $10.7 \pm 7.3$ \\
Unit (Mean \pm SD) & $6.1 \pm 4.8$ \\
Years of working in an IBD Unit (Mean \pm SD) & \\
Working center site & $22 / 20 / 11$ \\
$\quad$ Northern/Central/Southern & $67 / 24$ \\
$\quad \begin{array}{l}\text { Working center type } \\
\text { General hospital/Academic hospital }\end{array}$ & \\
\hline $\begin{array}{l}\text { Number of IBD patients on biologics followed } \\
<25 /<50 /<75 /<100 />100\end{array}$ & $48 / 19 / 6 / 10 / 8$ \\
\hline
\end{tabular}

IBD, inflammatory bowel disease; SD, standard deviation 
Table 2 Differences between IBD nurses and other nurses

\begin{tabular}{llll}
\hline Parameter & $\begin{array}{l}\text { IBD } \\
\text { nurses } \\
\mathrm{N}=34\end{array}$ & $\begin{array}{l}\text { Other } \\
\text { nurses } \\
\mathrm{N}=57\end{array}$ & P value \\
\hline $\begin{array}{l}\text { Educational level } \\
\text { (Degree/Master/Diploma) }\end{array}$ & $7 / 1 / 26$ & $2 / 2 / 53$ & 0.03 \\
$\begin{array}{l}\text { Working center type } \\
\text { (Academic vs. General }\end{array}$ & $13 / 21$ & $11 / 46$ & 0.047 \\
$\begin{array}{l}\text { Hospital) } \\
\begin{array}{l}\text { Working center site } \\
\text { (Northern/Central/ }\end{array}\end{array}$ & $9 / 16 / 9$ & $32 / 15 / 10$ & 0.02 \\
$\begin{array}{l}\text { Southern Italy) } \\
\begin{array}{l}\text { Number of IBD patients } \\
\text { on biologics } \\
\text { (>25 vs. <25) }\end{array}\end{array}$ & $23 / 11$ & $21 / 36$ & 0.0045 \\
\hline \begin{tabular}{l} 
IBD, inflammatory bowel disease \\
\hline
\end{tabular} & & & \\
\hline
\end{tabular}

than other nurses; they were more frequently operating in Central or Southern than in Northern Italy; they were working in an Academic center rather than in a General hospital and in IBD centers with $>25$ patients on biological therapies. In addition, the length of service in a Gastroenterology Unit tended to be longer for an IBD nurse than other nurses, although the difference failed to reach statistical significance (12.1 \pm 8.3 vs. $9.7 \pm 6.5$ years; $\mathrm{P}=0.053)$. On the contrary, mean age ( $47.8 \pm 7.2$ vs. $46.9 \pm 5.6$ years; $\mathrm{P}=0.8$ ), gender distribution (M/F: $7 / 27$ vs. $7 / 50 ; \mathrm{P}=0.3$ ), years of nursing (24.9 \pm 8.9 vs. 23.5. \pm 6.4 years; $\mathrm{P}=0.6$ ), and years working in the IBD unit (6.9 \pm 5.4 vs. $5.4 \pm 4.4$ years; $\mathrm{P}=0.09)$ did not significantly differ between IBD and other nurses.

A total of $49(53.8 \%)$ nurses provided one or more information on unmet needs for their specific professional training. The most frequent requests were: 1) to perform a specific theoretical training for caring IBD patients (33 nurses, $67.4 \%$ ); 2) to make a direct comparison of their nursing practice with that of other dedicated centers (15 nurses; 30.6\%); and 3) to complete a specific practical training (5 nurses; $10.2 \%$ ).

\section{Discussion}

An appropriate care for IBD patients requires a multidisciplinary approach, particularly for those patients with a more severe disease necessitating biological therapies $[1,11]$. Among different figures involved in such a team, the role of IBD nurse specialists is particularly relevant, since they can provide direct care as well as a holistic support [12,13]. Although the role of IBD nurses in improving health outcomes remains to be proven [14], there are increasing data supporting that they play a relevant role in some settings. For instance, they helpfully perform triage of IBD patients by a dedicated helpline. Indeed, IBD nurse specialists may provide appropriate and timely visits, with an obvious impact on both patients' satisfaction and use of health resources $[15,16]$. In
Europe, a formal IBD Nursing education is available in the UK, Austria, Czech Republic, Finland, Germany, The Netherlands, Spain and Sweden, and it is under development in Belgium and Denmark [5], and, more recently, in Italy [10]. In detail, the figure of both 'Fundamental IBD nurse' and 'Advanced IBD nurse' is delineated by the National Health System and by Italian College of Nursing [10,17].

We evaluated the presence of IBD nurses actually managing those IBD patients receiving biological therapies. Overall, the data of our nationwide survey show that less than $40 \%$ of IBD centers providing biological therapies can rely on an IBD nurse. Interestingly, we found that IBD nurses have a higher educational level and a longer experience in Gastroenterology Unit than non-dedicated nurses. Moreover, from our survey emerged that IBD are less frequently present in General Hospitals and in low-volume centers. All these observations suggest that the presence of IBD nurses needs to be implemented in Italy, particularly in low-volume centers and in non-academic Hospitals. Indeed, IBD patients on biological therapies should receive the same high-quality level of nursing, irrespective of the total number of patients managed. The lacking of IBD nurses in several Italian centers appears even more disappointing considering that in other countries even the role of Clinical Nurse Specialist is already recognized not only for IBD $[12,13,18]$, but also for diabetes, heart failure, rheumatology, etc. $[19,20]$. The IBD Clinical Nurse Specialist (or Advanced IBD Nurse) provides an advanced level of care with regard to IBD, and such a nursing stage is achieved only following a combination of extensive clinical practice, professional development and formal education (honors degree or master) $[9,12,13]$. In the UK, the number of IBD

\section{Summary Box}

\section{What is already known:}

- Management of inflammatory bowel disease (IBD) patients on biological therapies requires a multidisciplinary approach

- There are increasing data supporting that dedicated nurses play a relevant role in this setting

- A formal IBD Nursing education is available in different European countries, but not in Italy

\section{What the new findings are:}

- This Italian nationwide survey showed that less than $40 \%$ of IBD centers providing biological therapies rely on an IBD nurse

- More than half of the nurses currently caring for IBD patients receiving biological therapies expressed the need for theoretical and practical specialized training, suggesting that implementation of training in IBD nursing is largely required in Italy 
nurse specialists doubled in the IBD Service Provision between 2006 and 2010, suggesting a real need of such a figure [21].

Another relevant finding of this survey is that more than half of the nurses currently caring for IBD patients receiving biological therapies in Italy express the need for more theoretical and practical specialized training, suggesting that implementation of training in IBD nursing is largely required in our country. Contrary to the physicians, to gain funding to perform courses is not easy for nurses, as well as to obtain time away from clinical practice are often not considered high priority by Departments [12]. Therefore, we would suggest that all the organizations potentially involved in nurse teaching (Departments, Scientific Societies, National Patient Support Associations, etc.) should be aware of these difficulties and should encourage the nurses' professional education.

In conclusion, our nationwide survey showed that the presence of an IBD nurse is still lacking in the majority of Italian IBD centers where patients receive biological therapies, suggesting a prompt implementation.

\section{Acknowledgments}

Group:

The following members of the Italian IBD Nurses Study

Barbero Luisella (Asti), Volpe Maria Rosaria (Avellino), Minenna Angela (Bari), Serafini Claudia (Bassano del Grappa; Vicenza), Gris Elisa (Feltre; Belluno), Bacchetta Roberta (Borgomanero; Novara), Onidi Francesca Maria (Cagliari), Taci Angelo (Caltanissetta), Corso Fabrizio (Campobasso), Capaldi Antonella (Cassino, Frosinone), Mastronardi Ivana (Castellana Grotte, Bari), Sinatora Rita (Catanzaro), Grisoni Francesca (Como), Lacaria Giovanni, Longo Francesco, Marazita Caterina (Cosenza), Allocchio Barbara, Moreschi Oliva (Crema; Cremona), Zamboni Rita (Firenze, Ospedale Pediatrico Meyer), Biagini Silvia (Firenze, Ospedale Careggi), Di Pasquale Graziano, Gentile Maria Antonietta (Foggia), De Angelis Anna (Frosinone), Parigi Paola, Rivetti Aurelia, (Genova), Moratto Daniela (Gorizia), Ongarelli Cristina (La Spezia), Rivaroli Stefania (Latina), La Terza Laura (Matera), Turri Paolo (Milano), Montanaro Susy (Napoli), Vettorato Maria Grazia (Padova), Ciravolo Nicolina, Morana Giuseppe (Palermo), Luschi Ilaria, Pellegrini Daniela (Pisa), Corsini Emanuela (Pordenone), Dukic Giuliana, Ghini Susanna, Proverbio Fiorella (Ravenna), Azzolini Stefania, Costi Nanda (Reggio Emilia), De Sanctis Pamela, Gallina Domenica, Paolucci Enrico, Valente Silvana (Rieti), Sardi Romina (Roma, Ospedale San Camillo), Acchione Patrizia (Roma, Ospedale Pertini), Forestale Roberta, Puthiaveettil Reetha (Roma, Policlinico Tor Vergata), Schiavoni Elisa (Roma, Policlinico Gemelli), Scalamonti Silvia (Roma, Ospedale Sant'Andrea), Donati Antonella (Roma, Complesso Integrato Columbus), Di Nicola Nicoletta (Roma, Ospedale San Filippo Neri), Di Gravio Cinzia, Torcolacci Federica (Roma, Ospedale San Giovanni), Martino Giuseppina (San Giovanni Rotondo, Foggia), Fasano
Riccardo, Vassallo Antonella (Torino, Ospedale San Giovanni), Chiaroni Luca, Coppolino Maurizio, Lamanna Luigi, Locoro Stefania, Puddu Davide, Violino Ivana (Torino, Ospedale Maria Vittoria), Simonetto Stefania (Trento), Carrea Fiorella, Gualtiero Antonella (Vasto, Chieti), Storti Marco (Viterbo)

\section{References}

1. Mantzaris GJ, Viazis N, Polymeros D, Papamichael K, Bamias G, Koutroubakis IE. Clinical profiles of moderate and severe Crohn's disease patients and use of anti-tumor necrosis factor agents: Greek expert consensus guidelines. Ann Gastroenterol 2015;28:417-425.

2. Monstada I, Hovdeb $\emptyset$, Solberga IC, Mouma BA. Clinical course and prognosis in ulcerative colitis: results from population-based and observational studies. Ann Gastroenterol 2014;27:95-104.

3. Viazis N, Mantzaris G, Karmiris K, et al. Inflammatory bowel disease: Greek patients' perspective on quality of life, information on the disease, work productivity and family support. Ann Gastroenterol 2013;26:52-58.

4. Dignass A, Van Assche G, Lindsay JO, et al. The second European evidence-based consensus on the diagnosis and management of Crohn's disease: current management. J Crohns Colitis 2010;4:28-62.

5. Dignass A, Eliakim R, Magro F, et al. Second European evidencebased consensus on the diagnosis and management of ulcerative colitis: definitions and diagnosis. J Crohns Colitis 2012;6:965-990.

6. O'Connor M, Gaarenstroom J, Kemp K, Bager P, van der Woudee CJ. N-ECCO survey results of nursing practice in caring for patients with Crohn's disease or ulcerative colitis in Europe. J Crohns Colitis 2014;8:1300-1307.

7. Nightingale AJ, Middleton W, Middleton SJ, Hunter JO. Evaluation of the effectiveness of a specialist nurse in the management of inflammatory bowel disease (IBD). Eur J Gastroenterol Hepatol 2000;12:967-973.

8. Smith GD, Watson R, Roger D, et al. Impact of a nurse-led counseling service on quality of life in patients with inflammatory bowel disease. J Adv Nurs 2002;38:152-160.

9. O'Connor M, Bager P, Duncan J, et al. N-ECCO Consensus statements on the European nursing roles in caring for patients with Crohn's disease or ulcerative colitis. J Crohns Colitis 2013;7:744-764.

10. Proposta di accordo tra il Governo, le Regioni e le Province autonome di Trento e Bolzano per la promozione di percorsi diagnostici terapeutici assistenziali (PDTA) nelle malattie infiammatorie croniche dell'intestino e malattia di Crohn e Colite Ulcerosa. http://www.quotidianosanita.it/allegati/allegato1656975. pdf (accessed 2 July 2016).

11. Orlando A, Armuzzi A, Papi C, et al. The Italian Society of Gastroenterology (SIGE) and the Italian Group for the study of Inflammatory Bowel Disease (IG-IBD) Clinical Practice Guidelines: The use of tumor necrosis factor-alpha antagonist therapy in inflammatory bowel disease. Dig Liver Dis 2011;43:1-20.

12. Whayman K, Stansfield C, Duncan J, O'Connor M. Developing the role of the clinical nurse specialist in inflammatory bowel disease. Gastrointest Nurs 2012;10:22-27.

13. Whayman K, Stansfield C, Duncan J, O'Connor M. Developing the role of the clinical nurse specialist in inflammatory bowel disease. Part 2: scope of practice. Gastrointest Nurs 2012;10:22-29.

14. Hernández-Sampelayo P, Seoane M, Oltra L, et al. Contribution of nurses to the quality of care in management of inflammatory bowel disease: a synthesis of the evidence. J Crohns Colitis 2010;4:611-622.

15. Corrala JE, Yarurb AJ, Diaza L, Simmonsa OL, Sussman DA. 
Cross-sectional analysis of patient phone calls to an inflammatory bowel disease clinic. Ann Gastroenterol 2015;28:357-365.

16. Anderson G, Marsden E. Audit of an inflammatory bowel disease (IBD) telephone helpline set up and managed by IBD specialist nurses Gastrointestinal Nurs 2012;10:24-30.

17. Evoluzione delle competenze infermieristiche. ANOTE-ANIGEA News 2-2015 (online).

18. Torrejón A, Oltra L, Hernández-Sampelayo P, et al. Development of quality standards in inflammatory bowel disease management and design of an evaluation tool of nursing care. Rev Esp Enferm Dig 2013;105:262-271.
19. Phillips A. Starting patients on insulin therapy: diabetes nurse specialist views. Nurs Stand 2007;21:35-40.

20. Phillips CO, Singa RM, Rubin HR, Jaarsma T. Complexity of program and clinical outcomes of heart failure disease management incorporating specialist nurse-led heart failure clinics: a metaregression analysis. Eur J Heart Failure 2005;7:333-341.

21. Carter SC, Ruffing V, Patty-Resk C, Hicks D (eds). Core curriculum for rheumatology nursing. First Edition 2015.

22. The IBD Standards Group. IBD Standards 2013 update. Standards for the healthcare of people who have inflammatory bowel disease. www.ibdstandards.org.uk (accessed 2 July 2016). 
Age: Gender F M

City where you are working:

You are working in:

University Hospital General Hospital

Educational level:

Diploma Degree Master

How many years are you performing nursing?

How many years are you working in a Gastroenterology Unit?

How many years are you directly involved in IBD patient care?

You are caring for IBD patients more frequently in:

Medical division IBD-Dedicated ambulatory Ambulatory of gastroenterology Endoscopy Unit

How many IBD-patients on biological therapies are currently followed in your Unit?

$<25 \quad<50 \quad<75 \quad<100 \quad>100$

Your specific role for IBD patients on biological therapy consists in (one or more options):

Pre-biological therapy screening (HBV, TB, PAP-test, etc.)

To prepare the biological drug solution before administration

To administer biological therapy (infusion/injection patient's monitoring during infusion, etc.)

Helpline for patient's counseling (follow up, disease flare-up, etc.)

Nursing assistance during endoscoy of these patients

Your specific formation to care for IBD patients on biological therapy includes (one or more options):

N specific courses organized by your Departement for a total of days

$\mathrm{N}$ specific courses organized by a Pharmaceutical Company for a total of days

$\mathrm{N}$ specific courses organized by a Scientific Society for a total of days

N meetings/workshop on biological therapy in IBD patients

Practical training with a more skilled colleague

Continuous update on specialized Nursing Journals

Are you following the N-ECCO guidelines? Yes Not I do not know these guidelines

What are your unmet needs for a more specific formation: 